\title{
Tuberculosis Obstructive Pulmonary Disesase (TOPD)
}

\author{
Alcibey Alvarado González* \\ Internal Medicine and Neumology. Clínica de Diagnóstico Médico. San José, Costa Rica
}

\begin{abstract}
Chronic obstructive pulmonary disease (COPD) is a leading cause of morbidity and mortality worldwide. Tobacco smoking is established as a major risk factor. However, especially in the last 20 years, there are studies have shown that long-term exposure to biomass fuel smoke to cook and heat homes, also carries a high risk for the development of COPD. This occurs particularly in developing countries and it's estimated that 25-45\% of patients with COPD have never smoked and the burden of COPD not associated with smoking is possibly higher than previously believed. Although exposure to biomass is the major risk factor for COPD not associated with smoking, there are other associated factors such as occupational exposure to dust and gases, HIV/AIDS, lower respiratory tract infection (particularly in the childhood), chronic asthma, external pollution, poverty, and history of pulmonary tuberculosis (PTB). PTB affects more than 9 million people and kills 1.5 million people each year. Prevalence of airflow obstruction varies from $28 \%$ to $68 \%$ of patients with PTB and the association occurs mainly with the COPD phenotype. Such infection is associated with airway fibrosis, and the immune response to mycobacteria can result in airway inflammation, which is characteristic of COPD. The degree of airflow obstruction is correlated with the extent of the disease. This review exposes the evidence of this association (TOPD), and some clinical, functional, anatomopathological and therapeutic aspects and particularly the need for preventive interventions to face this other side of the entity (COPD not associated with smoking) that seems to be increasing.
\end{abstract}

\section{Introduction}

COPD is a common but still neglected disease, and it is the only common chronic disease that has steadily increased over the last 50 years and is now the third ranked cause of death after cardiovascular disease and stroke and affects over 400 million people in the world [1]. The World Economic Forum has estimated that the global costs of COPD will reach US $\$ 50$ trillion/yr by 2030 , making it more costly than cardiovascular disease [2]. With the increase in smoking in developing countries and the increase in the life expectancy in high-income countries it is expected that the prevalence will increase in the next 30 years, and it is like that in the year 2030 there will be a total of annual deaths higher than 4.5 million [3]. In these evaluations there is a subregistry, since most of these studies are carried out in smoking patients and nowadays the prevalence of COPD in non-smokers is increasing, associate with the use on biomass, other fuels, and environmental pollution [4]. According to World Health Organization (WHO) report, in the actuality, 9.6 million people developed active tuberculosis and 1.5 million died due to tuberculosis by year. It is the leading infectious cause of death globally $[5,6]$ and tuberculosis remains one of the 10 causes of death worldwide and in the last decade there have been around 100 million tuberculosis patients [7].

Past's history of pulmonary tuberculosis has recently emerged as a risk factor for later development of COPD. Post-tuberculous development of COPD is not a new thought; it has been mentioned in the literature in the past also [8-10]. Allwood, et al. named the condition of tuberculosis-associated obstructive pulmonary disease as TOPD [11]. However, it is still a matter of debate whether chronic airflow obstruction and TOPD are different or same entities. This monography will review the links between tuberculosis and COPD.

\section{The epidemiological basis of TOPD}

The relation between past's history of tuberculosis and later development of chronic airflow obstruction has been reported even in 1950 s and 1960s. However, the major drawback in early studies was lack of adequate controls; therefore, the confounding effect of smoking on airflow obstruction was not adjusted [12]. In a study done in 1955, the authors reported impairment of respiratory function in pulmonary tuberculosis patients [13], and in 1959, Gaensler, et al. reported evidence of airflow obstruction in $61 \%$ of 1533 tuberculosis patients [14]. In 1971, Snider, et al. evaluated 1403 patients of pulmonary tuberculosis admitted to a Chicago Municipal Tuberculosis Sanatorium from 1964 to 1966 and reported airflow obstruction in 23\% patients [15]. Lee, et al. analyzed the effects of previous tuberculosis on the risk of obstructive lung disease development. Total 294 subjects had evidence of previous tuberculosis on chest radiograph. After adjustment for sex, age, and smoking history, radiological evidence of previous tuberculosis was independently associated with airflow obstruction with the odds ratio of 2.56. The risk was present even in patients with minimal radiographic changes also [16].

In a nationwide survey of 13,826 adult in South Africa, results suggested that the strongest predictor of COPD was history of PTB: odds ratio 4.9 for men (95\% CI 2.6-9.2) and 6.6 (3.7-11.9) for women. Furthermore, the risk of COPD was more strongly associated with PTB than with tobacco smoking or exposure to smoke from biomass fuel [17]. The PREPOCOL study in 5 cities in Colombia reinforced the strong association of COPD with history of PTB (2.9, 1.6-5.5) [18] and the PLATINO study conducted in 5 in Latin American cities with a sample of 5571 patients also showed that the prevalence of COPD was $30.7 \%$ for patients with a history of PTB compared to $13.9 \%$ for

*Correspondence to: Alcibey Alvarado, Clínica de Diagnóstico Médico. Torre Médica. 3 piso. Paseo Colón, San José, Costa Rica, Tel: 50622237134, 50622566439, 50687351858; Fax: 50622216754; E-mail: alcialvagonza@yahoo. com.mx

Key words: chronic obstructive pulmonary disease (COPD), pulmonary tuberculosis (PTB), tuberculosis obstructive pulmonary disease (TOPD)

Received: June 20, 2021; Accepted: July 19, 2021; Published: July 22, 2021 
those without [19]. History of PTB increased the risk of COPD by 4.1 times for men and 1.7 times for women. The burden of obstructive lung disease (BOLD) study had also shown past's history of tuberculosis as a risk factor for developing airflow obstruction in later life with the adjusted odds ratio of 2.51 [20]. Allwood, et al. confirmed a positive association between past's history of tuberculosis and the presence of chronic airflow obstruction. This relationship was independent of cigarette smoking and biomass fuel exposure [21]. Byrne, et al. in another systematic review and meta-analysis found that the association between prior history of tuberculosis and the presence of COPD was strongest in never smokers and younger people ( $<40$ years). Development of chronic airflow obstruction also depends on the geographical area. It is higher in high tuberculosis incidence countries. The odds ratio of chronic airflow obstruction development were more than three times in countries with a reported tuberculosis incidence of more than 100/100.000 population/year [22].

In Indian studies, Brashier, Gothi and Verma, et al. reported between $13-46 \%$ of prevalence of airflow obstruction and the prevalence increased with the duration after treatment completion [2325]. Aggarwal D, et al. have shown that the association of COPD with PTB constitutes a significant proportion of COPD patients in India and that it has 2 different characteristics: it affects younger people than patients with conventional COPD and they have more hospitalizations, reaffirming the idea that TOPD is a distinct clinical entity [26]. Very recently it has been shown that young patients (from the age of 23), previously healthy and non-smokers can develop residual chronic changes post-PTB, one year after completing the treatment. These changes include gas trapping (33\%) and reduced DLCO (25\%) and this correlates with gas trapping evidenced in radiological images [27]. Histological study in these patients confirmed distortion of small pathways and blood vessels, conforming a phenotype other than COPD associated with smoking $[28,29]$.

More than 2 billion people (approximately one fourth of the world's population) are infected with Mycobacterium tuberculosis and $80 \%$ of people infected live in 22 countries, with a particularly high burden in Asian, African, and Latin American countries [30]. Therefore, it is likely that the cumulative burden of COPD associated with PTB is much greater than previously believed, particularly in developing countries. In the last edition of GOLD on COPD (2021), in the entire document, there are only 2 lines and 3 references that cite PTB as a risk factor for COPD and not as a cause and not even citing comorbidities in Chapter 6 [31]. Also, in African COPD guidelines, it is only cited as a risk factor with very few bibliographic citations [32]. In Costa Rica (a third world country in Latin America with a good health system) in an analysis of mortality from PTB (2016-2019), the authors found in the relevant registries as associated diseases Diabetes mellitus, cancer and "others " in $41 \%$ of the cases (this exposes the synergism between PTB, and other morbidities as causes of death) but COPD is not mentioned [33]. These data serve to exemplify the little information and possibly knowledge that exists about the relationship between PTB and COPD.

\section{Air Flow Obstruction Mechanism and Pulmonary Function In TOPD}

The pathophysiological mechanisms are not completely clear, but there are at least three factors involved.

The involvement of small airways $(<2 \mathrm{~mm}$ internal diameter and without cartilage) due to obliterative bronchiolitis is an important factor in countries with endemic tuberculosis [34]. In a series of obliterative bronchiolitis, $98 \%$ of the causes were infectious and within these, $78 \%$ were post-tuberculosis [24]. The characteristic radiological changes of bronchiolitis are air entrapment, thickening of the bronchial walls, and of centrilobular nodules. The high-resolution CT (HRCT) will show a reduced coefficient of attenuation in the expiratory phase of the CT scan. The CT scan should be performed with contrast medium (as requested in the CT protocol for the study of interstitial disease with ins and expiratory phases and in the prone position). There will be no differences in the attenuation coefficient (Hounsfield units) between both phases. This translates into gas trapping that is produced by bronchiolar obstruction [35]. The thickening of the bronchial wall occurs due to cellular infiltration and / or fibrosis and the involvement of the centrilobular nodules is consistent with the location of the bronchioles [36].

These radiographic findings may persist after successful antifimic treatment is completed. Patients with previously proven TB of the airways, nonsmokers, have more gas trapping, fibrosis, emphysema, and reduced carbon monoxide diffusion capacity than non-tuberculosis patients of the same age group [11].

Non-cystic bronchiectasis (BQCs) is a phenotype defined by the presence of BQCs in the absence of a genetic cause [37]. They are frequent in PTB in developing countries and especially in the presence of recurrent TBP. In West India $83 \%$ of BQCs are due to PTB [38]. BQCs occur due to endobronchial obstruction, peri-bronchial fibrosis, and / or bronchial obstruction by elongated lymphoid nodules. When occurring in areas of scarring they are known as traction BQCs. In patients with a lot of structural damage due to $\mathrm{PTB}$, it is common to find BQCs associated with atelectasis and emphysema on CT $[39,40]$.

Accelerated parenchymal destruction occurs due to imbalance proteases (destruction) / antiproteases (protection) generating pulmonary emphysema [31]. Matrix metalloproteinases (MMPs) are a group of endopeptidases that contain zinc, are calcium-dependent and that degrade the parenchymal matrix including elastin, collagen, laminin, fibronectin, aggrecan and proteoglycans that make up said matrix. They are produced by neutrophils, macrophages, and epithelial cells in response to IL-1B, TNF-a, and ROS (reactive oxygen species) [41]. Tissue inhibitors of MMPs (TIMPs) counteract the degrading effect of said endopeptidases. MMPs appear to mediate tissue remodeling in PTB and COPD [42]. MMP9 potentiates the stabilization of the tuberculous granuloma and MMP1 is secreted in reactivation of latent tuberculosis and is responsible for tuberculous cavitation. Therefore, MMPs are common mediators in both entities and could be the connection in TOPD [43]. In fact, from MMP1 to MMP9 are elevated in the BAL (bronchiole-alveola lavage) in patients with PTB and the levels show a correlation with tissue damage [44].

The maximum loss of lung function usually occurs in the first 6 months after diagnosis and stabilizes around 1.8 months after the end of treatment [45]. Structural damage increases with each reactivation and this correlates with an accelerated loss of FEV1. These alterations can establish themselves even after successful treatment [46]. Positive smear microscopy, extensive disease, little post-treatment radiological improvement, prolonged duration of therapy, initial failure in it, are independent predictors for developing TOPD. It is therefore obvious that an early diagnosis and treatment of tuberculosis reduces the risk [47]. Patients with radiological changes in PTB should be candidates for COPD screening according to GOLD criteria. The prevalence of airflow obstruction in PTB is estimated to be around $26.3 \%$ for subjects with radiological changes of PTB and its sequelae and is significantly higher 
than when there are no radiological changes. which suggests that when these exist there is already a considerable loss of lung function [48]. In Colombia, South Africa and Cameroon, tuberculosis is a greater risk factor for developing COPD than smoking and exposure to biomass [49]. The risk of COPD has been described with nontuberculous mycobacteria [50]. In most cases the obstruction is irreversible.

\section{Bidirectional Impact}

It seems clear that PTB can cause COPD. In fact, some authors propose that patients treated for PTB should be monitored longterm due to the risk of developing COPD [51]. But what is the risk for patients with COPD associated with smoking to develop PTB? Smoking is considered a powerful risk factor for developing PTB [52]. Tuberculous infection associated with smoking promotes that macrophage polarize towards the M1 / M2 phenotypes, increasing the production of MMP9 and MMP12, which generates a link between PTB and COPD [53]. In a study in China, the percentage of PTB in COPD patients was $45 \%$ (HRCT) and was associated with emphysema and increased lung damage [54]. In a study in a Swedish hospital, COPD patients had a 3 times higher risk of developing PTB than controls and the incidence of PTB was inversely related to FEV1 [55]. Cigarette smoke alters the protective immune response against Mycobacterium tuberculosis. For example, it reduces the levels of IL-1 and TNF- $\alpha$, which are important in the immune response to bacteria, favoring infection. In addition, the alveolar macrophages of patients with COPD associated with smoking are dysfunctional (regardless of the use or not of steroids), which carries an additional risk factor for TBP, since the macrophage is a key cell in the resolution of tuberculosis [56-58]. The use of oral or inhaled steroids (high doses) in COPD adds an additional risk factor for developing PTB as it produces immunosuppression that favors infection, although this is, with inhaled steroids, a controversial point. In countries with endemic PTB, it is recommended to rule out tuberculosis before starting inhaled or oral steroids in COPD [59].

\section{Immune Profile In TOPD}

The immune and inflammatory profile of TOPD has been little investigated. From Guieden's work, which has compared the concentrations of 29 cytokines in sputum, face-to-face, COPD / tobacco vs COPD/ post-PTB and both vs healthy controls, non-smokers or tuberculosis, several facts can be deduced. First, COPD related to tobacco use is more severe than the post-TB form. The pathogenesis of COPD in patients with a history of smoking involves several cytokines in the local pathway such as IL-1 $\alpha$, IL-1 $\beta$, IL-6, IL-17, TNF- $\alpha$, IL-8, MIP- $1 \beta$ and VEGF. In contrast the pathogenesis of the post-TB form seems to imply fewer inflammatory markers with IL-1RA, IL- $1 \beta$, GRO and $\mathrm{sCD} 40 \mathrm{~L}$ as local marker [60]. $\mathrm{t}$ is probable that the greater severity related to tobacco is a function of the irritative disturbances caused by smoking. They are more pronounced than those related to tuberculosis infection, since antifimic treatment eliminates the damage associated with mycobacteria, while in the smoker the damage persists until you develop COPD.

Cytokines of the IL-1 family (IL-1 $\alpha$, IL-1 $\beta$ and IL-1RA) intervene in the inflammatory process [61]. Levels of IL-1a were statistically higher in the COPD patients with a history of smoking compared to post-TB subgroup. The study found through association tests that IL-1a was strongly correlated with the clinical stage of the disease. Since the stage of COPD was more advanced in the COPD subgroup with a history of smoking, this could justify the greater presence of IL-1 $\alpha$ in smokers compared to patients with post-TB airflow obstruction. IL-1 $\alpha$ and IL$1 \beta$ could promote the production of other pro-inflammatory cytokines.
IL-6 does not significantly interfere with post-TB airflow obstruction (there was no difference between the COPD/post-TB subgroup and the control group in the level of IL-6). Levels of TNF- $\alpha$ were statistically significantly higher in the COPD patients with a history of smoking. Generally, the secretion of TNF- $\alpha$ in COPD is induced by tobacco smoke and maintained by the chronic inflammation process [62]. NF- $\alpha$ stimulates the migration of monocytes/macrophages and neutrophils into the epithelial airways. Macrophages and epithelial cells produce GRO, MIP-1 and IL-8. Since Mycobacterium tuberculosis is no longer presenting the post-TB airflow obstruction patients, there is no real inducing element of TNF- $\alpha$, which could justify its low concentration in COPD/post-TB patients. IL- 17 concentration in both subgroups of COPD patients were higher compared to the control group.

MIP-1 $\beta$, in a higher concentration was noted in the COPD patients with a history of tobacco compared to the control group. MIP-1 $\beta$ is a chemokine that induces lymphocyte migration and recognizes CCR5 receptors in T cells and macrophages. This chemokine was not strongly expressed in the post-TB airflow obstruction patients [60]. IL-8 is higher in COPD / tobacco since cigarette smoke is a powerful inducer of it, while GRO is a powerful chemotactic factor of neutrophils and adhesion and degranulation of endothelial cells and is higher in COPD / PTB, therefore, both could be markers, in sputum, of their corresponding type of airflow obstruction. SCD40L binds to CD40 of monocytes promoting their adhesion to the vascular endothelium and is elevated in COPD / post-PTB [63]. VEGF is a growth factor that promotes angiogenesis and is elevated in the sputum of COPD / tobacco patients. VEGF was strongly expressed in the sputum of COPD patients with a smoking history compared to the control group, and not expressed in the COPD patients with anterior TB [64].

What is not clear yet is how much of these differences impact the natural history of both types of COPD, its clinical expression and response to treatment. It is likely that in the future, specific therapies can be designed with small molecules and / or monoclonal antibodies that target these inflammatory mediators by offering upstream therapy for this pathology.

\section{Common risk factors}

Smoked. Smoking is a clear risk factor for COPD [65]. Also smoking is a risk factor for respiratory infection, particularly active PTB and mortality from PTB. The impact of smoking is greater in active disease than in the risk of infection, favoring its recurrence, loss of follow-up, greater disease severity, drug resistance, and slow sputum conversion $[66,67]$. The dual epidemic of PTB and smoking occurs in developing countries and the impact of smoking on tuberculosis can be significant, so smoking control should be part of the tuberculosis treatment strategy in these nations [68]. This concept has been endorsed by the International Union against TB. The immune response to mycobacteria produces a type of inflammation similar that of COPD. In fact, oxidative stress is a common pathway for both $[4,41]$.

Biomass. In developing countries, biomass exposure is the most important fuel that causes COPD not associated with smoking [69]. Studies in India, Nepal, and Brazil report biomass exposure as an independent risk factor for PTB. The odds ratio of developing active PTB in the studies by Mishra, et al. was 3.56 in people who used biomass for cooking compared to controls [71].

Low socioeconomic status (LSS). LSS is responsible for poor health-related quality of life in COPD and a risk factor for PTB [70,72]. Several factors that affect LSS increase the risk of PTB such as malnutrition, indoor air pollution, alcoholism, overcrowding, poor 
ventilation of homes, use of biomass, low educational level, availability of drinking water and age [73].

Diabetes Mellitus (DM). PTB, infects more than 2 billion people on the world. DM will affect 366 million patients in 2030. It is not surprising then that both entities concur. The incidence of PTB is 2-4 times higher in diabetics than in the general population [74]. DM increases the risk of PTB through several mechanisms. The high concentration of glucose "per se" favors infections in diabetic patients. Also, the altered immunity of diabetics favors infection by tuberculosis. Altered CD4 / CD8 ratio, neutrophilic granulocytic dysfunction (chemotaxis and phagocytosis), decreased number of circulating peripheral monocytes, and increased cytokines translate into a chronic inflammatory process that is common in diabetic and obese patients. In turn, malnutrition and physical inactivity stimulate, in tuberculosis patient, the release of glucagon, adrenaline and cortisol, predisposing to glucose intolerance. The high incidence of calcific chronic pancreatitis in patients with $\mathrm{PTB}$, leads to glucose intolerance. Vitamin deficiencies A, C and D are intertwined in the increased risk of PTB and DM. It seems that the risk of developing PTB is higher in the first year after DM diagnosis [75]. An improvement in glycemic control can reduce the risk of developing PTB and a comprehensive approach should be implemented to control the global burden of both [76]. The concurrence of PTB and DM in Pakistan is $14.8 \%$ [77]. The burden of DM among tuberculosis patients is higher than the prevalence of PTB in diabetics [78].

$\mathrm{DM}$ and metabolic syndrome are 2 comorbidities less well-known of COPD. While asthmatic patients do not have an increased risk of diabetes, patients with COPD, even minimal, have an increased risk (relative risk of 1.5-1.8) [79]. It does not seem to be related to the use of inhaled steroids, since patients with COPD who do not use them also develop diabetes and if seems to be related to the systemic inflammatory process since IL- 6 and TNF- $\alpha$ induce insulin resistance by blocking signals in the insulin receptor, increasing the risk of diabetes mellitus type 2 . The same profile of systemic inflammatory cytokines is found in metabolic syndrome. The use of systemic steroids does in COPD, favor the development of DM, particularly type 2 [80].

Recently, Fang, et al. found (in USA) that younger adults, Mexican Americans, and persons without health insurance were more likely to be untreated (monotherapy or combination therapy) when risk-factor targets were not achieved. These gaps are especially troubling given that rates of diabetes-related complications are higher in racial or ethnic minorities and uninsured populations and that type 2 diabetes that develops during young adulthood has a more aggressive clinical course than diabetes that occurs in later life [81]. These groups are, in developed countries, those that are also more susceptible to developing and transmitting PTB.

Vitamin D deficiency (VDD). VDD is a potential risk factor for both entities. Huang, et al. have described that VDD is more a risk factor for developing PTB than a consequence, but the beneficial role of vitamin D supplementation in the prevention and treatment of PTB is not clear [82]. Recent work suggests that VDD predicts the risk of developing tuberculosis disease in a level-dependent manner and that the risk is higher in HIV-positive patients with VDD [83]. Regarding the role of vitamin D in PTB, the following mechanisms appear to operate. Vitamin D activates cell death in macrophages that have ingested mycobacteria, through the activation of cathelicidin. They induce INF- $Y$ activity in these macrophages, as well as the production of reactive oxygen and nitrogen species that attack the mycobacteria. They also stimulate the genesis of phagolysosomes in infected macrophages, favoring phagocytosis and inhibit the MMPs that are important in the production of pulmonary cavitation in PTB. Vitamin D also operates in the adaptive immune response. From another perspective, vitamin D promotes insulin sensitivity, which is why VDD could reduce the secretion of insulin from the beta cells of the pancreas, promoting type 2 $\mathrm{DM}$, and in turn, favoring PTB. Despite these observations, prospective studies have not shown that vitamin D supplementation (14,000 IU D3 / week / 3 years) decreased the risk of primary tuberculosis infection or acute respiratory infection due to PTB in children [84].

Vitamin D plays a critical role in calcium / phosphorus homeostasis and maintenance of bone mass. It regulates corresponding hormonal activity and is involved in cell differentiation, assists in the function of the epithelial cells of the airway and in innate immunity in the lung. Epidemiological studies have linked VDD with an increased risk of lung infection. However, the results are conflicting regarding its role as a clinical biomarker in COPD and the impact of supplements on acute exacerbation of the disease. Beyond these considerations, VDD should be treated as another COPD comorbidity, particularly in patients with levels $<10 \mathrm{ng} / \mathrm{mL}$, particularly if exacerbations are frequent $[85,86]$. Vitamin D is required for lung development and if it's deficient, it has the potential to initiate chronic respiratory diseases at any age [87].

Small airways disease. In a recent publication, Allwood reported in a young patient, non-smoker, with sequelae of PTB, the anatomopathological confirmation of small airways disease (28). In COPD, myofibroblast populations increase in smokers and patients with COPD contributing to small airway fibrosis and obliteration. These changes might be driven by the process of epithelial to mesenchymal transition [88]. Therefore, the compromise of this "silent zone", functionally speaking of the airways, seems to be the connection between PTB and EPOC for TOPD. We need to understand the mechanisms of small airway fibrosis and the role of small airway fibroblasts, which may be regulated by mediators released from small airway epithelial cells and may involve new therapeutic approaches that target mechanisms of fibrosis and repair [89].

Chronic disease anemia is frequently found in PTB and COPD. In both entities, systemic inflammation leads to slow but substantial sarcopenia (loss of muscle mass), with skeletal muscle atrophy and cachexia [90].

Accelerated aging. There is increasing support for the view that COPD represents accelerated lung aging, resulting in the accumulation of senescent cells in the lungs of COPD patients [91]. Most cell types in the lungs of COPD patient show senescence and this may be accelerated by a loss of endogenous anti-aging molecules, such as sirtuin- 1 and sirtuin-6, which are markedly reduced in the lungs of COPD patients [92]. Senescent cells are in cell cycle arrest and lose their ability to repair damage. Oxidative stress is a major driving mechanism for cellular senescence (stress-induced senescence) leading to accelerated aging. This may account for the high frequency of comorbidities in COPD patients, many of which are also diseases of accelerated aging. Several therapies to target cellular senescence are now in development. Removal of senescent cells with senolytic drugs that promote cell apoptosis and removal are also in development and have already been tested in humans [93]. Senotherapies may be useful not only in COPD. but also, in its comorbidities in which the same molecular pathways of accelerated aging are also involved. There are no studies of accelerated senescence in PTB or TOPD, but since oxidative stress is a common pathway for all 3 entities, it is likely that metabolic pathways and treatments involving this mechanism will be defined in the future. 


\section{Treatment}

The treatment of TOPD is basically the same as that of conventional COPD, but there are some considerations that deserve to be highlighted. Fluticasone / salmeterol carries a higher risk of PTB than budesonide / formoterol. Possible mechanisms involved are, the elimination of fluticasone is slower than that of budesonide, the residence time in the tissue is therefore longer, fluticasone is 10 times more potent than budesonide in inhibiting the release of IL- 6 , IL- 8 and TNF- $\alpha$ and, also budesonide is less lipophilic so its residence time in human tissue is less, producing less immunosuppression [94]. In very much limited casuistry in patients with TLD (tuberculosis lung destroyed), significant improvement in FEV1 and FVC has been demonstrated with the use of tiotropium (18 $\mu$ g, once a day) [95], also a decrease in all causes of mortality [96], however, to validate these results it is required Randomized Clinical Trials with statistically powerful casuistry. The same happens with the use of Indacaterol $(150 \mu \mathrm{g}$, once a day) for 8 weeks. There is a significant improvement in respiratory function in patients with TLD, but consistent long-term results are not known [97].

The 5 most frequent comorbidities of TLD are: hypertension, DM; hyperlipidemia, GERD, and osteoporosis. Of the 10 deadly diseases worldwide COPD ranks $3^{\text {rd }}$ and PTB $10^{\text {th }}[98]$.

\section{Future Perspectives}

Consistent with Sarkar, here are several areas which are still unexplored at the present. First, we need to have large population-based case control study with patients of tuberculosis and asymptomatic normal population to prove the causality between tuberculosis and COPD. We need to explore the differences between TOPD and COPD in relation to clinical, physiological, radiological, airway inflammation, and response to treatment. Prospective studies are necessary to document inhaled bronchodilator treatment as the first line of therapy in TOPD, and particularly to define the use and indications of inhaled glucocorticoids.

\section{Conclusion}

Development of chronic airflow obstruction may be related to common risk factors or tuberculosis associated lung damages. Both COPD and tuberculosis are major health problem in developing countries. Early diagnosis and institution of adequate treatment of tuberculosis should be emphasized to reduce the future burden of COPD. Emphasis should also be given to avoid common risk factors like smoking and biomass fuel smoke exposure to prevent development of both tuberculosis and COPD in future.

\section{Authorship}

This work was only carried out by the author. Author AA contributed on the planning, data collection, data analysis, writing and critical review. AA read and approved the final manuscript.

\section{Source of economic support}

No.

\section{Conflict of interest}

No.

\section{References}

1. GBD Chronic Respiratory Disease Collaborators (2020) Prevalence and attributable health burden of chronic respiratory diseases, 1990-2017: a systematic analysis for the Global Burden of Disease Study 2017. Lancet Respir Med 8: 585-596. [Crossref]

2. Bafadhel M, Peterson S, De Blas MA, Calverley PM, Rennard SI, et al (2018) Predictors of exacerbation risk and response to budesonide in patients with chronic obstructive pulmonary disease: a post-hoc analysis of three randomized trials. Lancet Respir Med 6: 117-126. [Crossref]

3. WHO (2015) Projection of mortality and causes of death, 2015 and 2030, World Health Organization.

4. Alvarado A (2018) Chronic obstructive pulmonary disease in non-smokers: an update Clin Res Trials 4: 1-8.

5. Horsburgh CR, Barry CE, Lange C (2015) Treatment of tuberculosis. N Engl J Med 373:2149-2160. [Crossref]

6. WHO (2015) Global tuberculosis report Geneva: World Health Organization.

7. Van Kampen SC, Wanner A, Edwards M, Harries AD, Kirenga BJ, et al (2018) International research and guidelines on post-tuberculosis chronic lung disorders: a systematic scoping review: BMJ Global Health 3: e000745.

8. Anno H, Tomashefski JF (1955) Studies on the impairment of respiratory function in pulmonary tuberculosis. Am Rev Tuberc 71: 333-348. [Crossref]

9. Martin CJ, Hallett WY (1961) The diffuse obstructive pulmonary syndromes in a tuberculosis sanatorium. Incidence and symptoms. Ann Intern Med 54: 1156-1164. [Crossref]

10. Lancaster JF, Tomashefsk JF (1965) Tuberculosis- a cause of emphysema. Am Rev Respir Dis 87: 435-437. [Crossref]

11. Allwood BW, Gillespie R, Galperin-Aizenberg M, Bateman M, Olckers H, et al (2014) Mechanism of airflow obstruction in tuberculosis-associated obstructive pulmonary disease (TOPD) Am J Respir Crit Care Med 189: A5832.

12. Chakrabarti B, Calverley PM, Davies PD (2007) Tuberculosis and its incidence, special nature, and relationship with chronic obstructive pulmonary disease. Int $J$ Chron Obstruct Pulmon Dis 2: 263- 272. [Crossref]

13. Anno H, Tomashefski JF (1955) Studies on the impairment of respiratory function in pulmonary tuberculosis. Am Rev Tuberc 71: 333- 348. [Crossref]

14. Gaensler EA, Lindgren I (1959) Chronic bronchitis as an etiologic factor in obstructive emphysema: preliminary report. Am Rev Resp Dis 80: 185. [Crossref]

15. Sinder GL, Doctor L, Demas TA (1971) Obstructive airway disease in patients with treated pulmonary tuberculosis. Am Rev Resp Dis 103: 625- 640. [Crossref]

16. Lee SW, Kim YS, Kim DS, Oh YM, Lee SD (2011) The risk of obstructive lung disease by previous pulmonary tuberculosis in a country with intermediate burden of tuberculosis. J Korean Med Sci 26: 268- 271. [Crossref]

17. Ehrlich RI, White N, Norman R, Laubscher R, Stein K, et al (2004) Predictor of chronic bronchitis in South African adults. Int J Tuberc Lung Dis 8: 369-376. [Crossref]

18. Caballero A, Torres-Duque CA, Jaramillo C (2008) Prevalence of COPD in five Colombian cities situated at low, medium, and high altitude (PREPOCOL study). Chest 133: 343-349. [Crossref]

19. Meneses AMB, Pérez-Padilla R, Jardim JRB, Muiño A, López MV, et al. (2005) For the PLATINO Team. Chronic obstructive pulmonary disease in five Latin American cities (the PLATINO study): a prevalence study. Lancet 366: 1875-1881. [Crossref]

20. Amaral AF, Coton S, Kato B, Tan WC, Studnicka M, et al (2015) Tuberculosis associates with both airflow obstruction and low lung function: BOLD results. Eur Respir J 46:1104- 1112. [Crossref]

21. Allwood BW, Myer L, Bateman ED (2013) A systematic review of the association between pulmonary tuberculosis and the development of chronic airflow obstruction in adults. Respiration 86: 76- 85. [Crossref]

22. Byrne AL, Marais BJ, Mitnick CD, Lecca L, Marks GB (2015) Tuberculosis and chronic respiratory disease: a systematic review. Int J Infect Dis 32: 138- 146. [Crossref]

23. Brashier B, Gangavane S, Valsa S, Gaikwad SN, Ghorpade SV, et al (2007) Almost Half the Patients Treated for Pulmonary Tuberculosis Show Evidence of Obstructive Airways Disease. Stockholm, Sweden: European Respiratory Society Annual Congress. 
24. Gothi D, Shah DV, Joshi JM (2007) Clinical profile of diseases causing chronic airflow limitation in a tertiary care center in India. J Assoc Physicians India 55: 551-555. [Crossref]

25. Verna SK, Narayan KV, Kumar S (2009) A study on prevalence of obstructive airway disease among post pulmonary tuberculosis patients. Pulmon 11: 4-7.

26. Aggarwal D, Gupta A, Jarmeja AK, Bkardwaj M (2017) Evaluation of tuberculosisassociated chronic obstructive pulmonary disease at a tertiary care hospital: a casecontrol study. Lung India 34: 415-419. [Crossref]

27. Allwood BW, Maasdorp E, Kim GJ, Cooper CB, Goldin J, et al (2020) Transition from restrictive to obstructive lung impairment during treatment and follow-up of active tuberculosis. Int J Chron Obstruct Pulmon Dis 15: 1039-1047. [Crossref]

28. Allwood BW, Rigby J, Griffith-Richards S, Kamarek D, Preez L, et al (2019) Histopathological confirmed tuberculosis-associated obstructive pulmonary disease. Int J Tuberc Lung Dis 23: 552-554. [Crossref]

29. Kim HJ, Baek S, Kim HJ, Lee JS, Oh YM, et al (2015) The impact of smoking on airflow limitation in subjects with history of asthma and inactive tuberculosis. PLOS One 10: e0125020. [Crossref]

30. WHO Stop TB Partnership (2018) Tuberculosis in countries. [Crossref]

31. GOLD (2021) Global strategy for the Diagnosis, Management, and Prevention of Chronic Obstructive Pulmonary disease. Global Initiative for Chronic Obstructive Lung Disease.

32. Abdool-Gaffar MS, Ambaran A, Ainslie GM, Bollinger CT, Gefen L (2011) Guideline for the management of chronic obstructive pulmonary disease-2011 update. $S$ Afr Med $J$ 101: 61-73. [Crossref]

33. Mata AZ, Baraquiso PA (2020) Análisis de mortalidad por tuberculosis en Costa Rica. AMC 63: 126-129.

34. Alvarado A (2017) Bronchiolitis in adults: a review. Clin Res Trials. 31:1-7.

35. Tashtoush B, Okator NC, Ramírez JF, Smolley LS (2015) Follicular bronchiolitis: a literature review. J Clin Diagn Res 9: 0e01-0e05. [Crossref]

36. Devankonda A, Raoof S, Sung A, Tavis WD, Naidich B (2010) Bronchiolar disorders: a clinical-radiological diagnostic algorithm. Chest 137: 938-951. [Crossref]

37. Flume PA, Chalmers JD, Olivier KN (2018) Advances in bronchiectasis: endotyping, genetics microbiome, and disease heterogeneity. Lancet 392: 880-890. [Crossref]

38. Natanajan S, Rudnawar P (2014) Bronchiectasis in western India: clinical presentation and socioeconomic burden. J Indian Med Assoc 112: 89-92. [Crossref]

39. Chae JN, Jeng CY, Shim SW, Rho BH, Yeon YJ (2011) CT radiological findings in patients with tuberculosis destroyed lung and correlation with lung function. Tuberc Respir Dis 71: 202-209.

40. López-Campos JL, Calero C (2013) Infections causes of chronic obstructive pulmonary disease: TB or no TB; that is the question: Respiration 86: 15-16. [Crossref]

41. Alvarado A, Arce I (2015) Molecular biology of chronic obstructive pulmonary disease from the bases to the therapeutic decision: a review. BJMMR 10: 1-14.

42. Salgame $\mathrm{P}$ (2011) MMPs in tuberculosis granuloma creators and tissue destroyers. $J$ Clin Invest 121: 1686-1688. [Crossref]

43. Elkington P, Shiomit T, Breen R, Nuttall RK, Ugarte-Gill CA, et al (2011) MMP-1 drives immunopathology in human tuberculosis and transgenic mice. J Clin Invest 121 : 1827-1833. [Crossref]

44. Singh S, Kubberg A, Singh UK, Singh A, Prassad R, et al (2014) Antimycobacterial drugs modulate immunopathogenic matrix-metalloproteinases in a cellular model of pulmonary tuberculosis. Antimicrob Agents Chemother 58: 4657-4665. [Crossref]

45. Chung KP, Chen JY, Lee CH; Wu HO, Wang JY (2011) Trends and predictors of change in pulmonary function after treatment for pulmonary tuberculosis. Clinics 66: 549-556. [Crossref]

46. Hnizdo E, Singh T, Churchyard G (2000) Chronic pulmonary function impairment caused by initial and recurrent pulmonary tuberculosis following treatment. Thorax 55: 32-38. [Crossref]

47. Lee CH, Lee MC, Lin HH (2012) Pulmonary tuberculosis and delayed in antituberculosis treatment are important risk factors for chronic obstructive pulmonary disease. PLoS One 7: e37978. [Crossref]

48. Hwang YT, Kim JH, Lee CY, Park S, Park YB, et al (2014) The association between airflow obstruction and radiologic change by tuberculosis. $J$ Thorac Dis 6: 471-476. [Crossref]
49. Mbatchou NBH, Nouyep J, Nganda Metto M (2016) Post-tuberculosis lung function impairment in a tuberculosis reference clinic in Cameroon. Respir Med 114: 67-71. [Crossref]

50. Yeh JJ, Wan YC, Sung PC, Chou CY, Kao CH (2014) Non tuberculosis mycobacteria disease is a risk factor for chronic obstructive pulmonary disease: a nationwide cohort study. Lung 192:403-415. [Crossref]

51. Dhar R, Biswas B, Kulkarn T, Limaye S, Ghoshaj A (2018) Tuberculosis associated obstructive lung disease. A pilot-study. Eur Respir J 52: 4415.

52. Fayez EA, Moosavi SAJ, Kouranifer S, Delbandi AK, Teimourian S (2020) The effect of smoking on latent tuberculosis infection susceptibility in high-risk individuals in Iran. J Immunoassay Immunochem 41: 885-895. [Crossref]

53. Le Y, Ca DW, Zhou L, Fan X, Liu Q, et al (2020) Infection of Mycobacterium tuberculosis promotes both M1/M2 polarization and MMP production in cigarette smoke-exposed macrophage. Front Immunol 11: 1-14. [Crossref]

54. Jin J, Li S, Yu W, Lin X, Sun Y (2018) Emphysema and bronchiectasis in COPD patients with previous pulmonary tuberculosis: computed tomography features and clinical implications. Int J Chron Obstruct Pulmon Dis 13: 375-384. [Crossref]

55. Inghamman M, Ekbom A, Engstrom G, Ljunberg B, Romanus U, et al (2010) COPD and the risk of tuberculosis-a population-based cohort study. PLoS One 5: e10138. [Crossref]

56. Tang S, Ai H, Yao L, Hao X, Shen Y, et al (2013) Increased cytokines response in patients with tuberculosis complicated with chronic obstructive pulmonary disease. PLoS One 8: e62385. [Crossref]

57. Hiemstra PS (2019) Altered macrophage production in chronic obstructive pulmonary disease. Ann Am Thorac Soc 10: 5180-5185. [Crossref]

58. Holloway RA, Bonnally LE (2013) Immunopathogenesis of chronic obstructive pulmonary disease. Curr Opin Pulm Med 19: 95-102. [Crossref]

59. Brassard P, Scissa S, Kezouh A, Ernst P (2011) Inhaled corticosteroids and risk of tuberculosis in patients with respiratory diseases. Am J Respir Crit Care Med 183 675-678. [Crossref]

60. Guieden E, Perfura-Yone EW, Ikomey GM, Nkenfou CN, Mesembe M, et al (2020) Cytokine profile in the sputum of subjects with post-tuberculosis airflow obstruction and in those with tobacco related chronic obstructive pulmonary disease. $B M C$ Immunol 21: 52. [Crossref]

61. Botolho FM, Bauer CMT, Finch D, Nikota JK, Zavitzc CJ, et al (2011) IL-1 $\alpha /$ IL-1R expression in chronic obstructive pulmonary disease and mechanistic relevance to smoke in mice. PLoS One 6: e28457.

62. Li X-N, Xue P, Dong Q (2014) Imbalances of Th17 and Treg cells and their respective cytokines in COPD patients by disease stage. Int J Clin Exp Med 5324-5329. [Crossref]

63. Elise G, George MI, Céline N, Walter P-YE, Martha M (2018) Chronic obstructive pulmonary disease (COPD): neutrophils, macrophages, and lymphocytes in patients with anterior tuberculosis compared to tobacco related COPD. BMC Res Notes 11: 192. [Crossref]

64. Sichelstiel A, Yadava K, Trompette A, Salami O, Iwakura Y, et al (2014) Targeting IL$1 \mathrm{~b}$ and IL-17A driven inflammation during influenza-induced exacerbations of chronic lung inflammation. PLoS One 9: e98440. [Crossref]

65. Thun MJ, Carter BD, Feskanisch D, Freedman ND, Prenitise R, et al (2013) 50-yeartrends in smoking-related mortality in the United States. N Engl J Med. 368:351-364 [Crossref]

66. Yen YF, Yen MY, Lin YS, Lin YP, Shih HC, et al (2014) Smoking increases risk of recurrence after successful antituberculosis treatment: a population-based study. Int $J$ Tuberc Lung Dis 18: 492-498. [Crossref]

67. Jayashree K, Kathirvel S, Shewade HD, Kaur H, Goel S (2016) Smoking Cessation Interventions for Pulmonary Tuberculosis Treatments Outcomes. Cochrane Database Syst Rev 1: CDO11125. [Crossref]

68. Salvi SS, Barnes PJ (2009) Chronic obstructive pulmonary disease in non-smokers Lancet 374: 733-743. [Crossref]

69. Pokhrel AK, Bates MN, Verna SC, Toshi HS, Sreeramateddy CT, et al (2010) Tuberculosis and indoor biomass and kerosene use in Nepal; a case-control study: Environ Health Perspect 118: 558-564. [Crossref]

70. Kanercisto M, Vasankari T, Laifinen T, Heliöuwara M, Jousilatha P, et al (2011) Low socioeconomic status is associated with chronic obstructive airway diseases. Respir Med 105: 1140-1146. [Crossref] 
71. Mishra UK, Retherford RD, Smith KR (1999) Biomass cooking fuels and prevalence of tuberculosis in India. Int J Infect Dis 3: 119-129. [Crossref]

72. Gupta D, Das K, Balanighesh T, Aggahwal AN, Jindal SK (2014) Role of socioeconomic factors in tuberculosis prevalence. Indian J Tuberc 51: 27-31.

73. Narasimhan P, Wood J, Macintyres CR, Mashai D (2013) Risk factors for tuberculosis Pulm Med 293: 828939. [Crossref]

74. WHO (2015) Global Status Report on Non-communicable disease. 2014. World Health Organization (WHO) Geneva.

75. Pizzol D, Di Genaro F, Chaganlal KD, Fabrizio C, Monno S, et al (2016) Tuberculosis and diabetes: currents facts and future perspectives. Trop Med Int Health 21: 694-702. [Crossref]

76. Hayashi S, Chandramohan D (2018) Risk of active tuberculosis among people with diabetes mellitus: systematic reviews and meta-analysis. Trop Med Int Health 23: 10581070. [Crossref]

77. Tahir Z, Ahmad MD, Akhtar AM, Yaqub T, Mushtaq MN, et al (2016) Diabetes mellitus among tuberculosis patients: a cross sectional study from Pakistan. Afr Health Sci 16: 671-676. [Crossref]

78. Workneh MH, Bjune GA, Yimer SA (2017) Prevalence and associated factors of tuberculosis and diabetes mellitus comorbidity: a systematic review. PLoS One 12: e0175925. [Crossref]

79. Mannino DM, Thorn D, Swensen A, Holguin F (2008) Prevalence and outcomes of diabetes, hypertension, and cardiovascular disease in chronic obstructive pulmonary disease. Eur Respir J 32: 962-969. [Crossref]

80. Glasser S, Kruger S, Merkel M, Brawlage P, Herth FJ (2015) Chronic obstructive pulmonary disease and diabetes mellitus: a systematic review of the literature. Respiration 89: 253-264.

81. Fang M, Wang DMS, Coresh J, Selvin E (2021) Trends in Diabetes Treatment and Control in U.S. Adults, 1999-2018. N Eng1 J Med 384:2219-2228.

82. Huang SJ, Wang XH, Liu ZD, Cao WL, Han Y, et al (2016) Vitamin D deficiency and the risk of tuberculosis: a meta-analysis. Drug Des Develop Therapy 11: 91-102. [Crossref]

83. Aibana O, Huang CC, Aboud S, Armedo-Pena A, Becerra M, et al (2019) Vitamin D status and risk of incidence of tuberculosis disease: A nested case-control study, systematic review and, individual participant data meta-analysis. PLoS Med 16: 1-26. [Crossref]

84. Ganmaa D, Uyanga B, Zhou X, Gantsetseg G, Delgerekh B, et al (2020) Vitamin D supplements for prevention of tuberculosis infection and disease. $N$ Engl J Med 383 : 359-368. [Crossref]
85. Burkes RM, Ceppe A, Doerschuk CM, Couper D, Hoffman EA, et al (2020) Associations among 25-hydroxyvitamin D levels, lung function and, exacerbation outcomes in COPD: an analysis of the SPIROMICS cohort. Chest 157: 856-865. [Crossref]

86. Milne S, Sin DD (2020) Vitamin D deficiency in COPD. Biomarker treatable trait just a common comorbidity? Chest 157: 755-756. [Crossref]

87. Foong RE, Zosky GR (2013) Vitamin D deficiency and the lung: disease initiator or disease modifier? Nutrients 265: 28280-1900. [Crossref]

88. Eapen MS, Lu W, Hackett TL, Singhera GK, Mahmood MQ, et al (2021) Increased myofibroblasts in the small airways, and relationship to remodeling and functiona changes in smokers and COPD patients: potential role of epithelial-mesenchymal transition. ERJ Open Research 7: 00876-2020. [Crossref]

89. Barnes PJ (2019) Small airway fibrosis in COPD. Int J Biochem Cell Biol 116: 105598. [Crossref]

90. Barnes PJ, Celli BR (2009) Systemic manifestations and comorbidities of COPD. Eur Respir J 33: 1165-1185. [Crossref]

91. Barnes PJ, Baker J, Donnelly LE (2019) Cellular senescence as a mechanism and target in chronic lung diseases. Am J Respir Crit Care Med 200: 556-564. [Crossref]

92. Koo HK, Vasilescu DM, Booth S, Hsieh A, Katsamenis OL, et al (2018) Small airways disease in mild and moderate chronic obstructive pulmonary disease: a cross-sectional study. Lancet Respir Med 6: 591-602. [Crossref]

93. Barnes PJ (2020) COPD 2020: new directions needed. Am J Physiol Lung Cell Mol Physiol 319: 884-886. [Crossref]

94. Huang TM, Kuok C, Wang YM, Wang CY, Lai CE, et al (2020) Risk of active tuberculosis among COPD patients treated with fixed combinations of long-acting Beta 2 agonists and inhaled corticosteroids. BMC Infect Dis 20: 706.

95. Yum HK, Park IN (2014) Effect of inhaled tiotropium on spirometric parameters in patients with tuberculosis destroyed lung. Tuberc Respir Dis (Seoul) 77: 167-171. [Crossref]

96. Kim HC, Kim TH, Kim Y J, Rhee CK, Oh YM (2019) Effect of tiotropium inhaler use on mortality in patients with tuberculosis destroyed lung: based on linkage between hospital and national wide health insurance claims data South Korea. Ther Clin Risk Manag 20: 85. [Crossref]

97. Kim CJ, Yoon HK, Park MJ, Yoo KH, Jung KS, et al (2017) Inhaled indacaterol fo the treatment of COPD patients with destroyed lung by tuberculosis and moderate-to severe airflow limitation: results from randomized INFINITY study. Int Chron Obstruct Pulmon Dis 12: 1589-1596. [Crossref]

98. Han D, Lee HY, Kim K, Kim T, Oh YM, et al (2019) Burden and clinical characteristics of high grade of tuberculosis lung destroyed study: a nation-wide study. J Thorac Dis 11: 4224-4233. [Crossref]

Copyright: (C2021 González AA. This is an open-access article distributed under the terms of the Creative Commons Attribution License, which permits unrestricted use, distribution, and reproduction in any medium, provided the original author and source are credited. 